\title{
Serogroups, K1 antigen, and antimicrobial resistance patterns of Aeromonas spp. strains isolated from different sources in Mexico
}

\section{Ramón I Arteaga Garibay, Ma Guadalupe Aguilera-Arreola, Armando Navarro 0 caña*, Silvia Giono Cerezo, Miroslava Sánchez Mendoza**, José Molina López*, Carlos Eslava Campos*, Alejandro Cravioto*, Graciela Castro-Escarpulli/ ${ }^{+}$}

Departamento de Microbiología, Escuela Nacional de Ciencias Biológicas, Instituto Politécnico Nacional, Apartado Postal CON
174 CP 06400 México, D. F. *Departamento de Salud Pública, Facultad de Medicina, Universidad Nacional Autónoma de
México, Ciudad Universitaria, CP 04510 México D. F. **Laboratorios Estatales de Salud Pública de Hidalgo, Pachuca, Hidalgo

A total of 221 strains of Aeromonas species isolated in Mexico from clinical (161), environmental (40), and food (20) samples were identified using the automated system bioMérieux-Vitek®. Antisera for serogroups 01 to 044 were tested using the Shimada and Sakazaki scheme. The Kl antigen was examined using as antiserum the O7:K1C of Escherichia coli. Besides, we studied the antimicrobial patterns according to Vitek AutoMicrobic system.

Among the 161 clinical strains $60 \%$ were identified as A. hydrophila, $20.4 \%$ as A. caviae, and $19.25 \%$ as A. veronii biovar sobria. Only A. hydrophila and A. veronii biovar sobria were found in food (55 and $90 \%$ respectively) and environmental sources (45 and 10\% respectively). Using "O" antisera, only 42.5\% (94/221) of the strains were serologically identified, 55\% (121/221) were non-typable, and 2.5\% (6/221) were rough strains. Twenty-two different serogroups were found, O14, O16, O19, O22, and 034 represented $60 \%$ of the serotyped strains.

More than 50\% of Aeromonas strain examined (112/221) expressed K1 encapsulating antigen; this characteristic was predominant among Aeromonas strains of clinical origin. Resistance to ampicillin/sulbactam and cephazolin was detected in 100 and 67\% of Aeromonas strain tested for their susceptibility to antibiotics. In conclusion, antibiotic-resistant Aeromonas species that possess the K1 encapsulating antigen and represent serogroups associated with clinical syndrome in man are not uncommon among Aeromonas strains isolated from clinical, food and environmental sources in Mexico.

Key words: Aeromonas - serogroups - resistance patterns - K1 antigen

The genus Aeromonas is composed of a large number of different taxa. Currently this group is included in the family Aeromonadaceae, at least 17 genome-species are recognized in the genus (Martin-Carnahan \& Joseph 2005). However, A. hydrophila, A. caviae, and A. veronii biovar sobria are considered human pathogens since they are related with intestinal and extraintestinal infections, including septicemia, wounds, and respiratory tract disease (Janda 1991). Previous studies have demonstrated that the genus Aeromonas is the second cause of gastroenteritis in children and the fifth in adult patients (Janda 2001).

Serologic typing is based on the presence of specific somatic "O" antigen. The Aeromonas genus has 96 serogroups: the 45 serogroups proposed by Sakasaki and Shimada (1984) include rough strains obtained from mesophilic Aeromonas strains and 52 serogroups from different strains isolated in England, Peru, Brazil, and Australia (Thomas et al. 1990). In these serologic schemes,

Financial support: CGPI 20030305, 20050013 IPN, Mexico MGAA and RIAG are fellows from CONACyT and PIFI, SGC received COFAA, and EDD, IPN supports and GCE received COFAA, EDD, IPN supports and SNI.

${ }^{+}$Corresponding author: chelacastro@ hotmail.com

Received 19 September 2005

Acepted 7 March 2006 several important serogroups have been defined, such as the O11 serogroup, which is related to extraintestinal infections including septicemia, meningitis, and peritonitis, whereas the $\mathrm{O} 34$ group has been found responsible for wound infections, and the $\mathrm{O} 16$ serogroup related to gastroenteritis (Merino et al. 1996, Janda 2001, Figueras 2005). A capsular polysaccharide has been found in serogroups $\mathrm{O} 11$ and $\mathrm{O} 34$ and this structure has been reported to play a role in the pathogenecity of virulent strains of $A$. salmonicida (Martínez et al. 1995). Therefore, serological typing methods are useful to relate characteristic Aeromonas spp. serogroups with virulence and several diseases. Epidemiological markers, including prevalence and geographical distributions, provide knowledge about the sources of the pathogenic characteristics and transmission mechanisms of infections produced by the Aeromonas genus.

In other microorganisms, the antigen structure has been used in epidemiological studies to define routes of transmission or relationships with pathogenicity. E. coli is serogically heterogeneous but has been classified based on its antigens, and specific serogroups can be associated with reproducible and certain clinical syndromes. These studies have been used to establish which strains are present in different countries (Sarff \& McCraken 1975, Nataro \& Kaper 1998). Although Aeromonas is associated with diseases in very young humans and in older inmunocompromised patients who often require antimicrobial therapy, reports about the susceptibility of these 
organisms to antimicrobial agents are limited in our country. The antibiotic susceptibility patterns may serve as important therapeutic and diagnostic guidelines and preestablish epidemiological markers, since few studies have focused on the isolation and characterization of Aeromonas species in Mexico (Castro-Escarpulli et al. 2002a,b).

The aim of this study was to determine the serogroups distribution, presence of the $\mathrm{K} 1$ antigen, and resistance patterns to antimicrobial agents exhibited by Aeromonas strains isolated from different sources in Mexico.

\section{MATERIALS AND METHODS}

Bacterial strains - Included in the study 221 strains: 161 from clinical specimens (140 from human feces and 21 from urine), 20 from food samples, and 40 environmental sample (16 freshwater and 24 sediments).

Biochemical identification - The strains were identified using the Vitek AutoMicrobic system (Vitek ASM, bioMérieux ${ }^{\circledR}$ Vitek, France) and complementary biochemical tests: production of acetylmethylcarbinol (Voges Proskauer), esculin hydrolysis, salicin fermentation, and gas production from glucose.

Serotyping - Serological typing was performed according to the antigenic scheme pattern proposed by Sakasaki and Shimada (1984). Antisera were prepared at the Facultad de Medicina, UNAM, Mexico, as previously reported (Thomas et al. 1990), using reference strains kindly provided by Dr B Rowe, Head of Enteric Pathogens Central Laboratory of Public Health, London, England.

$K 1$ antigen determination - Five colonies from those grown on Tripticase soy agar (TSA, Oxoid, UK) were suspended in $3 \mathrm{ml}$ of Tripticase soy broth (TSB, Oxoid), adjusted to 0.5 with the McFarland standard (1.5-10 ${ }^{8}$ cells $\mathrm{ml}^{-1}$ ) and then $5 \mu \mathrm{l}$ of this suspension was added to antiserum-agar $(0.5 \mathrm{mg} / \mathrm{ml}$ of capsular anti-K1 was mixed with $1 / 10 \mathrm{v} / \mathrm{v}$ TSB plus $1.5 \%$ agarose). After incubation at $37^{\circ} \mathrm{C}$ for $24 \mathrm{~h}$, presence of a precipitation reaction zone surrounding the colonies indicated the presence of the $\mathrm{K} 1$ antigen. E. coli $\mathrm{O} 7: \mathrm{KC} 1$, E. coli $\mathrm{O} 5: \mathrm{H} 4$, A. hydrophila ATCC $7966^{\mathrm{T}}$, A. caviae ATCC $15468^{\mathrm{T}}$, and A. veronii biovar sobria ATCC $35624^{\mathrm{T}}$ strains were used as controls (Sarff \& McCraken 1975).

Antimicrobial susceptibility testing - The resistance pattern of all strains to different antimicrobial agents was determinate by the Vitek AutoMicrobic system (Vitek ASM, bioMérieux ${ }^{\circledR}$ Vitek, France) with the GNS-110 card, containing: amikacin $(2-32 \mu \mathrm{g} / \mathrm{ml})$, ampicillin $(0.5-32 \mu \mathrm{g} / \mathrm{ml})$, ampicillin/sulbactam $(2-32 \mu \mathrm{g} / \mathrm{ml})$, cephazolin $(4-64 \mu \mathrm{g} / \mathrm{ml})$, cefotaxime $(6-24 \mu \mathrm{g} / \mathrm{ml})$, cefotetan $(4-64 \mu \mathrm{g} / \mathrm{ml})$, ceftazidime (4-64 $\mu \mathrm{g} / \mathrm{ml})$, ceftriazone $(16-128 \mu \mathrm{g} / \mathrm{ml})$, ciprofloxacin (1-4 $\mu \mathrm{g} / \mathrm{ml})$, gentamicin $(0.5-8 \mu \mathrm{g} / \mathrm{ml})$, imipenem $(4-8 \mu \mathrm{g} / \mathrm{ml})$, ofloxacin $(1-10 \mu \mathrm{g} / \mathrm{ml})$, piperacillin $(8-64 \mu \mathrm{g} / \mathrm{ml})$, tircarcillin/ clavulanic acid (16-64 $\mu \mathrm{g} / \mathrm{ml})$, tobramycin $(0.5-8 \mu \mathrm{g} / \mathrm{ml})$, and trimethoprim/sulfamethoxazole $(40-160 \mu \mathrm{g} / \mathrm{ml})$. A. hydrophila ATCC $7966^{\mathrm{T}}$, A. caviae ATCC $15468^{\mathrm{T}}$, and $A$. veronii biovar sobria ATCC $35624^{\mathrm{T}}$ strains were used as controls.

\section{RESULTS}

Identification of 221 Aeromonas strains to species level resulted in $65.2 \%$ being A. hydrophila, $19.2 \%$ A. veronii bt sobria and $14.9 \%$ A. caviae. In clinical samples, $A$. hydrophila was the predominant species $(60.2 \%)$, followed by A. caviae (20.5\%), and A. veronii bt sobria (19.3\%). A. hydrophila and A. veronii bt sobria were identified in 55 and $45 \%$ of the food samples and in 90 and $10 \%$ of the environmental samples, respectively. A. caviae was not found in food and environmental samples. Distribution of Aeromonas species according to sources of isolation is shown in Table I.

Of the Aeromonas strains serotyped with "O" serogroup antisera, 42.5\% (94/221) were typable, 55\% (121/ 221 ) were non-typable and $2.5 \%$ (6/221) were rough strains. Twenty-two different serogroups were found with $\mathrm{O} 14$, O16, O19, O22, O34 representing 60\% of the typable strains. The O14 (6/74), O16 (7/74), O19 (6/74), O22 (38/ $74)$, O34 (7/74) serogroups were most commonly associated with the 74 typable clinical Aeromona strains; whereas serogroup O22 (38/94) was observed in Aeromonas strains from the three different sources. Distributions of serogroups with respect to species and sources of isolation in shown in Table II.

Capsular antigen - Fifty-one percent (112 of 221) of all Aeromonas strains reacted positively with the antiserum $\mathrm{O} 7 \mathrm{KC} 1$ of $E$. coli . The $\mathrm{K} 1$ antigen was observed in $81.2 \%$ clinical, $12.5 \%$ environmental, and $6.4 \%$ food samples depicting Aeromonas strains (Figure).

Antimicrobial susceptibility testing - Testing the 221 Aeromonas strains against the 16 different antibiotics revealed that $100 \%$ were resistant to ampicillin and ampicillin/sulbactam. The clinical strains were resistant to cephazolin $(67 \%)$, cefotaxime $(3 \%)$, cefotetan $(2 \%)$, ceftazidime (2\%), ceftriaxone (2\%), ciprofloxacin ( $2 \%)$, gentamicin $(1 \%)$, imipenem $(1 \%)$, ofloxacin $(1 \%)$, piperacillin (2\%), tircarcillin/clavulanic acid (1\%),

TABLE I

Distribution of Aeromonas species by isolation origin

\begin{tabular}{lcccc}
\hline & \multicolumn{4}{c}{ No. (\%) positive for } \\
\cline { 2 - 5 } Species & $\begin{array}{c}\text { Clinical } \\
(\mathrm{n}=161)\end{array}$ & $\begin{array}{c}\text { Food } \\
(\mathrm{n}=20)\end{array}$ & $\begin{array}{c}\text { Environmental } \\
(\mathrm{n}=40)\end{array}$ & $\begin{array}{c}\text { Total } \\
(\mathrm{n}=221)\end{array}$ \\
\hline A. hydrophila & $97(60.2)$ & $11(55)$ & $36(90)$ & $144(65.2)$ \\
A. veronii biovar sobria & $31(19.2)$ & $9(45)$ & $4(10)$ & $44(19.9)$ \\
A. caviae & $33(20.4)$ & 0 & 0 & $33(14.9)$ \\
\hline
\end{tabular}

$\mathrm{n}$ : number strains 
TABLE II

Distribution of Aeromonas "O" serogroups with respect to species and origin

\begin{tabular}{|c|c|c|c|c|c|c|c|c|}
\hline \multirow[b]{3}{*}{ Serogroups } & \multicolumn{8}{|c|}{ No. $(\%)$ positive for } \\
\hline & \multicolumn{3}{|c|}{$\begin{array}{l}\text { Clinical } \\
(\mathrm{n}=74)\end{array}$} & \multicolumn{2}{|c|}{$\begin{array}{l}\text { Environmental } \\
\quad(\mathrm{n}=14)\end{array}$} & \multicolumn{2}{|c|}{$\begin{array}{l}\text { Food } \\
(n=6)\end{array}$} & \multirow[t]{2}{*}{$\begin{array}{c}\text { Total } \\
(\%)\end{array}$} \\
\hline & A. $h$ & A.c & A.v.s & A.h & A.v.s & A.h & A.v.s & \\
\hline 02 & 1 & & & & & & & $1(1)$ \\
\hline 08 & 2 & 1 & & & & & & $3(3)$ \\
\hline 09 & & & & & & & 1 & $1(1)$ \\
\hline 010 & 1 & & & & & & & $1(1)$ \\
\hline 013 & 1 & & & & & & & $1(1)$ \\
\hline 014 & 4 & 1 & 1 & & & & & $6(6)$ \\
\hline 015 & 2 & 1 & & & & & & $3(3)$ \\
\hline 016 & 6 & & 1 & & & & & $7(7)$ \\
\hline 019 & 5 & 1 & & & & & & $6(6)$ \\
\hline 020 & 1 & & & & & & & $1(1)$ \\
\hline 022 & 12 & 6 & 5 & 11 & & 2 & 2 & $38(41)$ \\
\hline 025 & 1 & 1 & & & 1 & & & $3(3)$ \\
\hline 026 & & 1 & & & & 1 & & $2(2)$ \\
\hline 027 & 1 & & & & & & & $1(1)$ \\
\hline 029 & & 1 & & & & & & $1(1)$ \\
\hline 033 & 1 & & & & & & & $1(1)$ \\
\hline 034 & 4 & 3 & & & & & & $7(7)$ \\
\hline 035 & 1 & 1 & 1 & & & & & $3(3)$ \\
\hline 037 & 1 & 1 & & 1 & & & & $3(3)$ \\
\hline 039 & & & & & 1 & & & $1(1)$ \\
\hline 044 & 1 & 1 & & & & & & $2(2)$ \\
\hline 045 & 2 & & & & & & & $2(2)$ \\
\hline Total & $47(50)$ & 19(20) & $8(9)$ & $12(13)$ & $2(2)$ & $3(3)$ & $3(3)$ & $94(100)$ \\
\hline
\end{tabular}

n: number of serogrouped strains; A.h: A. hydrophila, A.c: A. caviae, A.v.s: A. veronii biovar sobria.

tobramycin and trimethoprim/sulfamethoxazole (3\%), and susceptible to amikacin.

Aeromonas strains from environmental and food samples were resistant to cephazolin (35 and 55\%, re-

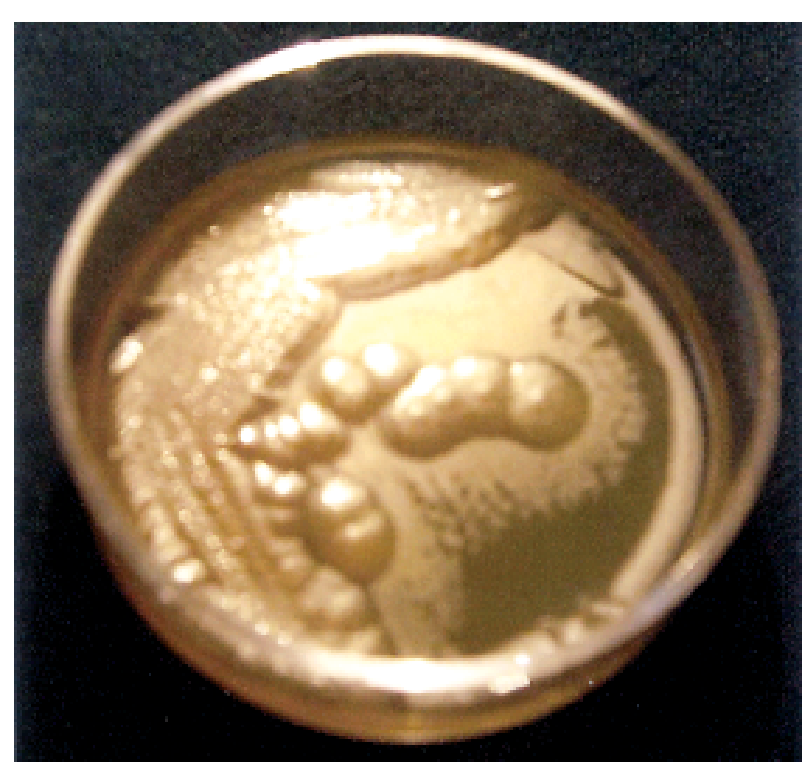

K1 immunoprecipitation around colonies of Aeromonas on TSA agar plus capsular anti-K1. spectively) and all strains were susceptible to amikacin, cefotaxime, cefotetan, ceftazidime, ceftriaxone, ciprofloxacin, gentamicin, imipenem, ofloxacin, piperacillin, tircarcillin/clavulanic acid, tobramycin, and trimethoprim/ sulfamethoxazole.

\section{DISCUSSION}

Distribution of the identified Aeromonas strains showed that $A$. hydrophila species (144 of 221) was the most frequently distributed among the group of strains coming from the three different sources (clinical, environmental, and food). These results are similar to those published by Janda et al. (1996) in which the most frequent species was $A$. hydrophila independently from the source. The 33 identified strains as A. caviae were all from clinical but not environmental or food sources. These results are accordance with previous studies, which described that A. caviae is the most common aeromonad isolated from diarrheic stool specimens (Mokracka et al. 2001, CastroEscarpulli et al. 2002a,b). Infections caused by Aeromonas might come from exposure to environmental or food sources, but its geographical localization, hygienic and sanitary conditions, and other factors related with pathogenic characteristics should not be ignored (Janda 1991). The antigen diversity of the Aeromonas genus has suggested that its serological typing, based on the somatic antigen, is useful (Sakazaki \& Shimada 1984, Thomas et 
al. 1990). Nevertheless, these schemes are not speciesspecific. Aeromonas strains isolated in Mexico belonged to the $\mathrm{O} 14, \mathrm{O} 16, \mathrm{O} 19, \mathrm{O} 22$, and $\mathrm{O} 34$ serogroups. The high incidence observed for the $\mathrm{O} 34$ serogroup agrees with previous studies performed with Aeromonas strains isolated from different origins (Janda et al. 1996, Misra et al. 1989, Merino et al. 1991). This serogroup has been associated with human infections, such as septicemia (Martínez et al. 1995).

There are no previous reports about the $\mathrm{O} 22$ serogroup as related with the incidence or isolation of Aeromonas strains. In the United States and India, serogroups $\mathrm{O} 11$ and $\mathrm{O} 16$ are considered the most frequent. In the present work, $\mathrm{O} 22$ serogroup was the most frecuent serogroup of the typable Aeromonas strains isolated from differences sources in Mexico. This finding provides evidence that the distribution of serogroup among Aeromonas strains could be related with their geographic localization (Kokka \& Janda 1990).

The presence of the polysaccharide K1 capsular antigen was mainly related with $81.2 \%$ of the Aeromonas strains from clinical sources. The K1 capsular antigen in Aeromonas has been related with biochemical and structural distribution of the capsular antigen belonging to group II (K1) of E. coli. This is important since some authors consider that the capsular antigen is related to serum complement resistance and participates in the adhesion in cell lines, as well as exhibiting anti-phagocytic capacity (Zhang et al. 2002).

The three species identified showed $100 \%$ resistance to ampicillin and ampicillin/sulbactam; while $A$. hydrophila and $A$. veronii bt sobria showed resistance to cefazolin (60 and 55\%, respectively). These correlated with previous reports in which the resistance had been determined to cephalosporins with similar patterns as those observed in Aeromonas strains from clinical and environmental origins (Overman \& Janda 1999, Castro-Escarpulli et al. 2002a).

McNicol et al. (1980) reported that $57 \%$ of the environmental Aeromonas isolates recovered in Chesapeake Bay and areas surrounding Dacca and the Matlab region of Bangladesh were resistant to multiple antibiotis. In our study, no antibiograms similar to those described above were obtained. These differences might be related to the source or recovered Aeromonas species, the method of isolation, the frequency of use of certain antimicrobial agents in a specific geographic area, or to other unknown factors. Our results show that the second and third generation cephalosporins and quinolones (ciprofloxacin and ofloxacin) are among the drugs with the best antimicrobial effect against Aeromonas spp.

The present work indicates that in Mexico there are many serogroup differences among Aeromonas spp., evidencing that the distribution of strains is related with their geographic localization. In conclusion, antibiotic-resistant Aeromonas species that possess the K1 encapsulating antigen and represent serogroup associated with clinical syndromes in man are not uncommon among Aeromonas strains isolated from clinical, food, and environmental sources in Mexico.

\section{ACKNOWLEDGMENTS}

To Dr B Rowe and T Cheasty from the Pathogenic Enterics Department in London, England, for providing reference strains and Delia Licona for laboratory support.

\section{REFERENCES}

Castro-Escarpulli G, Aguilera-Arreola MG, Giono Cerezo S, Hernández-Rodríguez CH, Rodríguez Chacón M, Soler Falgás L, Aparicio Ozores G, Figueras Salvat MJ 2002a. El género Aeromonas. ¿Un patógeno importante en México? Enf Infec y Microbiol 22: 206-216.

Castro Escarpulli G, Peña del Barrio D, Castañeda N, García Azcuaga A, Morier Díaz L, Aguilera-Arreola G, Bravo Farias L 2002b. Virulence factors of A. caviae strains isolated from acute diarrheic disease in Cuba. Rev Latinoam Microbiol 44: $11-13$

Figueras MJ 2005. Clinical relevance of Aeromonas. Rev Med Microbiol 16: 145-153.

Janda JM 1991. Recent advances in the study of the taxonomy, pathogenicity and infectious syndromes associated with the genus Aeromonas. Clin Micrbiol Rev 4: 397-410.

Janda JM 2001. Aeromonas and Plesiomonas. In M Susman, Molecular Medical Microbiology, Academic Press, San Diego, p. 1237-1270.

Janda JM, Sharon L, Abbot SL, Kashe S, Kellog GH, Shimada T 1996. Further studies on biochemical characteristics and serologic properties of the genus Aeromonas. J Clin Microbiol 34: 1930-1933.

Kokka RP, Janda JM 1990. Isolation and identification of autoagglutinating serogroup O:11 Aeromonas strains in the clinical laboratory. J Clin Microbiol 28: 1297-1299.

Martin-Carnahan E, Joseph WS 2005. Aeromonas. In DJ Brenner, NR Krieg, JT Staley, GM Garrity (eds), Bergey's Manual of Systematic Bacteriology, 2nd Ed., Vol. 2, SpringerVerlag, New York, p. 556-578.

Martinez M, Simon-Pujol JD, Congregado F, Merino S, Rubires X, Tomas J 1995. The presence of capsular polysaccharide in mesophilic Aeromonas hydrophila serotypes O:11 and O:34. FEMS Microbiol Lett 128: 69-73.

McNicol LA, Aziz KM, Huq I, Kaper JB, Lockman HA, Remmers EF, Spira WM, Voll MJ, Colwell RR 1980. Isolation of drug-resistant Aeromonas hydrophila from aquatic environments. Antimicrob Agents Chemother 17: 477-483.

Merino S, Camprubi S, Tomas JM 1991. The role of lipolysaccharide in complement-killing of Aeromonas hydrophila strains serotype 0:34. J Gen Microbiol 137: 1583-1590.

Merino S, Rubires X, Aguilar A, Tomas JM 1996. The O:34 antigen lipopolysaccharide as an adhesin in Aeromonas hydrophila. FEMS Microbiol Lett 139: 97-101.

Misra SK, Shimada T, Bhadra RK, Pal SC, Nair GB 1989. Serogroups of Aeromonas species from clinical and environmental sources in Calcuta, India. J Diarrhoeal Dis Res 7: 8-12.

Mokracka J, Krzyminska S, Szczuka E 2001. Virulence factors of clinical isolates of Aeromonas caviae. Folia Microbiol (Praha) 46: 321-326.

Nataro JP, Kaper JB 1998. Diarrheagenic Escherichia coli. Clin. Microbiol. Rev 11: 142-220. 
Overman TL, Janda JM 1999. Antimicrobial susceptibility patterns of Aeromonas jandaei, A. schubertii, A. trota and A. veronii biotype veronii . J Clin Microbiol 37: 706-708.

Sakazaki R, Shimada T 1984. O-Serogrouping scheme for mesophilic Aeromonas, strains. Japan. J Med Sci Biol 37: 247255.

Sarff DL, McCraken G 1975. Epidemiology of Escherichia coli $\mathrm{K} 1$ in healthy and diseased newborns. The Lancet
Saturday 17 May.

Thomas LV, Gross RJ, Cheasty T, Rowe B 1990. Extended serogrouping scheme for motile mesophilic Aeromonas species. J Clin Microbiol 28: 980-984.

Zhang YL, Arakawa E, Leung KY 2002. Novel Aeromonas hydrophila PPD134/91 genes involved in O-Antigen and capsule biosynthesis. J Infect Inmm 70: 2326-2335. 